\title{
Simulation of Surface Plasmon Resonance Biosensor Based on Nanoparticle Coreshell in $633 \mathrm{~nm}$
}

\author{
Widayanti ${ }^{1,2, *}$, Abraha $\mathrm{K}^{2}$, Utomo A.B ${ }^{2}$ \\ ${ }^{1}$ Physics Department, Faculty of Science and Technology, UIN Sunan Kalijaga Yogyakarta \\ J1. Marsda Adisucipto No 1 Yogyakarta 55281, Indonesia. Tel. +62-274-540971, Fax. +62-274-519739. \\ ${ }^{2}$ Physics Department, Faculty of Science and Mathematics, Universitas Gadjah Mada, \\ Bulaksumur, Caturtunggal, Kec. Depok, Kabupaten Sleman, Daerah Istimewa Yogyakarta 55281 Indonesia \\ *Email: salma_wida@yahoo.com
}

\begin{abstract}
Widayanti, K Abraha, A.B Utomo. 2017. Simulation of Surface Plasmon Resonance Biosensor based on Nanoparticle Coreshell in $633 \mathrm{~nm}$. Proc Internat Conf Sci Engin 1: 81-83. In this research, we developed the modeling and simulated the biosensor based on Surface Plasmon Resonance (SPR) phenomenon which detected the analyte i.e DNA. This SPR biosensor consists four layers where one of thus layers is the composite material. This nanocomposite spherical nanoparticle consisting of a spherical $\mathrm{Fe}_{3} \mathrm{O}_{4} @ \mathrm{Au}_{\mathrm{c}}$ core covered by $\mathrm{Au}$ shell, were applied as active material for DNA detection in $633 \mathrm{~nm}$. Here, we present the simulation of detection amplification technique through Attenuated Total Reflection (ATR) spectrum. Here, SPR system using the Kretschmann configuration, whereas the dielectric function determination of composite coreshell nanoparticle using Effective Medium Theory approximation. Finally, the reflectivity calculation was investigated by varied the size of the core and the shell of the coreshell. The refractive index of the prism is 1,723 ; the refractive index of $40 \mathrm{~nm} \mathrm{Ag}$ thin film is $0.13455+3,98651 \mathrm{i}$ and the refractive index of the composites were variated dependent the size of nanoparticle coreshell. Our results show that by varying the radius of core and shell thickness, the peak of the reflectivity (ATR spectrum) was shifted to the different angle of incident light. From its result, we can conclude that the addition of coreshell in SPR biosensor leads to enhancement the biosensor sensitivity in DNA detection.
\end{abstract}

Keywords: Surface Plasmon Resonance, DNA, Coreshell, Biosensor, $633 \mathrm{~nm}$

\section{INTRODUCTION}

Currently, there is great interest in the development of magnetic and plasmonic nanoparticle as an active material for biomolecules detection. The new nanoparticle combine multiple functions not obtainable in individual material have attracted considerable attention because of its development technology increase performance of surface plasmon resonance (SPR) biosensor (Wang et.al, 2010). The coating of $\mathrm{Au}$ metal for magnetic core material, prevents the oxidation and aggregation hence enhance the stabilisation of coreshell obviously. Whereas, the advantages brought about by current SPR biosensor is high sensitivity, spectrum large turnability from visible to infra-red, label free and real time detection. SPR is a kind of electromagnetic resonances that exist when there is an interface between metal and dielectric (Stuart et al, 2005; Jain et al, 2007), very sensitive for size, shape and the refractive index of material that contact with the metal. In the conventional SPR biosensor, when the biomolecules (DNA/ Deoxyribonucleic acid) keep contact to the metal surface, it get adsorbed on its surface and the refractive index is increased. The detection of DNA was shown at the ATR spectrum where the reflectivity of biosensor was decreased. If we added this biosensor with the composites consisting coreshell nanoparticle $\mathrm{Fe}_{3} \mathrm{O}_{4} @ \mathrm{Au}$, the reflectivity will be shifted to the right. It is happens because the effective refractive index of material on the metal surface was changed. The involvement of coreshell nanoparticles caused enhancement the biosensor sensitivity. The different size of $\mathrm{Fe}_{3} \mathrm{O}_{4} @ \mathrm{Au}+\mathrm{DNA}$ composites leads to change the resonance angle in SPR. In this paper, we investigated the ATR spectrum of three and four multilayers biosensor based on SPR with coreshell addition and DNA as sensing analyte.

\section{MATERIALS AND METHODS}

In this research we use the analytical, simulation and computational approximation to modeling the biosensor configuration which contains four layers. And then calculate reflectivity in Attenuated Total Reflection (ATR) and determinate the effective dielectric constant of composite (mixing of Fe3O4@Au and DNA were embedded in PEG/Polyethylene Glycol). Here, we used the Kretschmann configuration (Kretschmann and Raether, 1968) with 4 layers, prism/ Ag/ composite/ DNA+air, is shown in figure $1 . \theta_{i}$ and $\theta_{r}$ are the incident and the reflection angle, $k_{z}$ is the wave vector component at $z$ axis, and $d$ is the thickness of the each layer

The composite layer is shown in figure 1 where contain the inclusion material (Fe3O4@Au+DNA) and the host material (PEG). Composite model contain the complex particles (inclusion) and host material. In this SPR configuration, we have been carried out for refractive index of the SF10 glass prism used was 1,7230 , wavelength of electromagnetic wave was 633 $\mathrm{nm}$, the complex refractive index of silver was 
$n=0,13455+3,98651$ I (Johnson and Christy, 1972), dielectric constant of DNA is $\varepsilon=1,7769$ and the air was $n=1,0$ ( Whu et.al, 2010). The thickness of Ag film was $d=40 \mathrm{~nm}$, for composite $d=20 \mathrm{~nm}$. And then, the reflectivity $R$ is given by by Fresnel equation (Rather, 1986).

$$
R=\left|r_{i j k}\right|^{2}=\left|\frac{n_{i j}+r_{j k} e^{2 i k_{j x} d_{j}}}{1+r_{i j} r_{j k} e^{2 i k_{j z} d_{j}}}\right|^{2}
$$

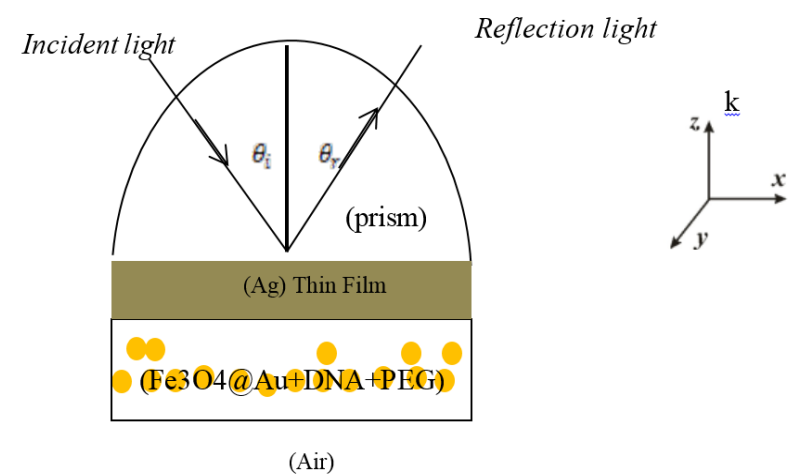

Figure1. Biosensor base on SPR with $\mathrm{Fe}_{3} \mathrm{O}_{4} @ \mathrm{Au}$ coreshell.

$r_{i j}=\frac{k_{i} \varepsilon_{j}-k_{j} \varepsilon_{i}}{k_{i} \varepsilon_{j}+k_{j} \varepsilon_{i}}$

\section{A spherical coreshell $\mathrm{Fe}_{3} \mathrm{O}_{4} @ \mathrm{Au}$ simulation}

$\varepsilon_{\mathrm{affl}}=\varepsilon_{g} \frac{a^{\mathrm{a}}\left(\varepsilon_{c}+2 \varepsilon_{g}\right)+2 b^{\mathrm{a}}\left(\varepsilon_{c}-\varepsilon_{g}\right)}{a^{\mathrm{a}}\left(\varepsilon_{c}+2 \varepsilon_{g}\right)-b^{\mathrm{a}}\left(\varepsilon_{c}-\varepsilon_{g}\right)}$

\section{Effective Permittivity of composite $\left(\mathrm{Fe}_{3} \mathrm{O}_{4} @ A u\right.$ $+D N A+P E G)$}

The effective permittivity of composite $\varepsilon_{\text {eff }}$ calculated with neglecting the correlation between the inclution material (complex material / $\mathrm{Fe}_{3} \mathrm{O}_{4} @ \mathrm{Au}+\mathrm{DNA}$ ) and host material (PEG), can be employ using the Maxwell Garnett formula (Chen et.al, 1998).

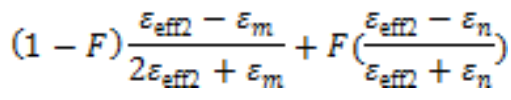

With $\varepsilon_{n}=\varepsilon_{1} \frac{\left(2 \varepsilon_{1}+\varepsilon_{2}\right)+2 \alpha\left(\varepsilon_{2}-\varepsilon_{1}\right)}{\left(2 \varepsilon_{1}+\varepsilon_{2}\right)-\alpha\left(\varepsilon_{2}-\varepsilon_{1}\right)}$

were $\alpha=\left(\frac{r_{0}}{R}\right)^{3}, r_{0}$ is the radius of $\mathrm{Fe} 3 \mathrm{O} 4 @ \mathrm{Au}, R$ is the radius complex particle (Fe3O4@Au +DNA), $F$ is the fraction volume of inclusion material to the host material, $\varepsilon_{n}$ is the dielectric constant of complex particle and $\varepsilon_{m}$ is the dielectric constant of host material.

\section{Biosensor Sensitivity}

The calculation of the sensitivity of biosensor base on the SPR is written (Verma et.al, 2011).

$S=\frac{\Delta \theta_{\mathrm{sp}}}{\Delta n}=\frac{\theta_{s p}\left(\varepsilon_{d}+\Delta \varepsilon_{d}\right)-\theta_{\mathrm{sp}}\left(\varepsilon_{d}\right)}{\Delta n}$

Where $\Delta \theta_{s p}$ is the difference of the angle of SPR and $\Delta n$ is the change in refractive index. While, the enhancement sensitivity value of SPR biosensor with coreshell compare with the conventional SPR is written (Adhib and Abraha, 2011).

$\Delta S=\frac{S_{\text {graph }}-S_{\text {lvon }}}{S_{\text {lvon }}} \times 100 \%$

\section{RESULTS AND DISCUSSION}

The changes of the radius of core and the thickness of shell, leads to the change the effective permittivity of coreshell. Whereas the change of radius inclusion material leads to change of the effective permittivity of composite. Therefore if that complex particles applied to SPR biosensor system, this change leads to the enhancement of the sensitivity of this biosensor. We can show from the reflectivity spectrum that the resonant angle shift to the right. Table 1 shows the effective permittivity of coreshell (equation 3 ) and the effective permittivity of composite can obtained from equation 4

Table 1. The Effective Permittivity of $\mathrm{Fe}_{3} \mathrm{O}_{4} @ \mathrm{Au}$ coreshell for the variation and the effective permittivity of composite with fraction volume (F) variation

\begin{tabular}{llll}
\hline $\boldsymbol{b} / \boldsymbol{a}$ & $\boldsymbol{\varepsilon}_{\text {effl }}$ & $\begin{array}{l}\boldsymbol{\varepsilon}_{\text {eff }} \\
\mathrm{F}=0.1\end{array}$ & $\mathrm{~F}=0.8$ \\
\hline $\mathbf{4 . 5 / 5}$ & $1.1078+3.05177 \mathrm{i}$ & $2.56269+0.003145 \mathrm{i}$ & $3.635097+0.01432 \mathrm{i}$ \\
$\mathbf{4 . 0 / 5}$ & $-2.32358+2.9429 \mathrm{i}$ & & \\
$\mathbf{9 . 0 / 1 0}$ & $1.1078+3.05177 \mathrm{i}$ & $2.64925+0.248526 \mathrm{i}$ & $3.67777+0.110574 \mathrm{i}$ \\
$\mathbf{8 . 0 / 1 0}$ & $-2.32358+2.9429 \mathrm{i}$ & & \\
$\mathbf{1 8} / \mathbf{2 0}$ & $1.1078+3.05177 \mathrm{i}$ & $2.89414+1.791472 \mathrm{i}$ & $3.816389+0.33528 \mathrm{i}$ \\
$\mathbf{1 6} / \mathbf{2 0}$ & $-2.32358+2.9429 \mathrm{i}$ & & \\
\hline
\end{tabular}


Table 1 shows that for $b / a=0.9$ resulting the effective permittivity $\varepsilon_{\text {effl }}=1.1078+3.05177 \mathrm{i}$. Then for $b / a=0.8$ resulting the effective permittivity $\varepsilon_{\text {effl }}=$ $2.32358+2.9429 \mathrm{i}$. The reflectivity from SPR biosensor based on nanoparticles coreshell are shown in figure 2 and figure 3. If the layer consist only thePrism and thin film of metal $40 \mathrm{~nm} \mathrm{Ag}$ (konvensional SPR), the peak of reflectivity at the angle $43.37 \mathrm{deg}$ (blue line). After the composite added on the surface of the Ag thin film, the peak of reflectivity shifted to the large angle. From figure 3. For the fraction volume of the composite is 0.1 and the thicknesses of the radius of $\mathrm{Fe}_{3} \mathrm{O}_{4} @ \mathrm{Au}$ is variated from $5 \mathrm{~nm}$ to $20 \mathrm{~nm}$, the resonance angle of SPR shift to the large angle. Increasing radius of $\mathrm{Fe}_{3} \mathrm{O}_{4} @ \mathrm{Au}$ leads to increase of the angle degree of resonance. The figure shows that at $5 \mathrm{~nm}$ (magenta line) dan $10 \mathrm{~nm}$ (black line) the minimum reflectivity is the best performance at $46.01 \mathrm{deg}$ and $46.23 \mathrm{deg}$, whereas from figure 5 , for the fraction volume of the composite is 0.8 and the thicknesses of the radius of $\mathrm{Fe}_{3} \mathrm{O}_{4} @ \mathrm{Au}$ is variated from $5 \mathrm{~nm}$ to $20 \mathrm{~nm}$, the resonance angle of SPR shift to the large angle too. The figure shows that at $10 \mathrm{~nm}$ the minimum reflectivity is the best performance at $48.37 \mathrm{deg}$. Therefore from equation (7), calculation of the sensitivity resulting the sensitivity increase $6.08 \%$, $6.59 \%$ for $\mathrm{F}=0.1$ and $11.52 \%$ for $\mathrm{F}=0.8$. Compare with sensitivity of SPR biosensor without coreshell addition.

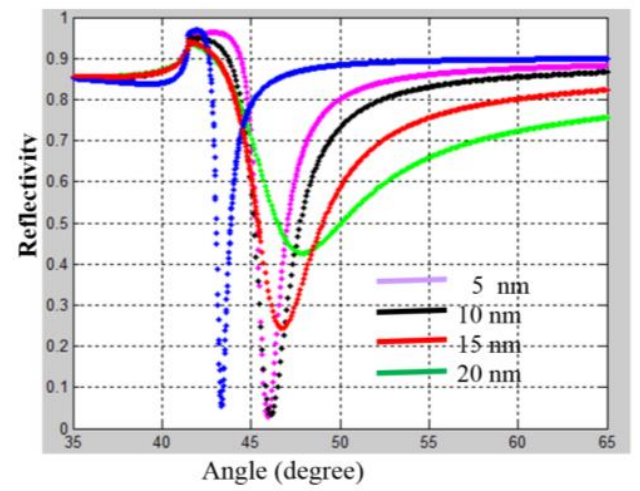

Figure 2. The reflectivity of ATR spectrum for the volume fraction of the composite $\mathrm{F}=0.1$. The radius of inclusion material at $\mathrm{R}=20 \mathrm{~nm}$ and. The radius of coreshell variated from $5 \mathrm{~nm}$ to the $20 \mathrm{~nm}$ with variated.

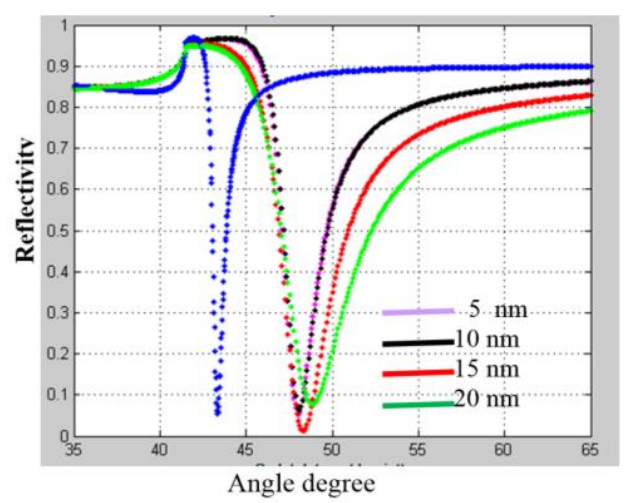

Figure 3. The reflectivity of ATR spectrum for the volume fraction of the composite $\mathrm{F}=0.8$. The radius of inclusion material at $\mathrm{R}=20 \mathrm{~nm}$ and. The radius of coreshell variated from $5 \mathrm{~nm}$ to the $20 \mathrm{~nm}$ with variated.

\section{CONCLUSIONS}

The combination of properties of magnetic material and plasmonic material lead to the enhancement of sensitivity of SPR biosensor that apply to detect existence of DNA. By vary the radius of core $\left(\mathrm{Fe}_{3} \mathrm{O}_{4}\right)$ and shell $(\mathrm{Au})$, the refractive index of coreshell changes and leads to change the permittivity of composite. The change of effective permittivity of composite (coreshell+DNA+PEG) lead to change position of the peak of reflectivity spectrum to the large angle. The SPR dips were shifted when coreshell were added on the composite as the active material that detects. This large shift in the dip angle suggest the potential for application in highly sensitive biosensor, in this case sensing biomolecules as analyte.

\section{REFERENCES}

Adhib M and Abraha K. 2011. Enhancement of sensitivity in Surface Plasmon Resonance Biosensor Using graphene materials: A theoretical prediction. Proceeding of the 3rd International Conferences And Workshop On Basic And Applied Sciences Bandung. Preprint

Chen L F, Ong C K and Tan B T G. 1998. Effective permittivity of layered dielectric Journal of Material Science 335891 5894.

Chettier U K and Engheta R. 2012. Internal homogenization: Effective permittivity of a coated sphere Optics Express $\mathbf{2 0}$ 22976-22986

Jain P K, Huang X, El-Sayed I and El-Sayed M. 2007. Review of Some Interesting Surface Plasmon Resonance-enhanced Properties of Noble Metal Nanoparticles and Their Application to Biosystem Plasmonics 2 107-118

Johnson P B and Christy R W. 1972. Optical Constans of The Noble Metals Phys Rev B 6 No 12

Kretschmann E and Raether H. 1968. Radiative Decay of NonRadiative Surface Plasmons Excited by Light. Zeitschrift Naturforsh 23 A 2135-2136

Rather H. 1986. Surface Plasmons on Smooth and Rough Surfaces and on Gratings Berlin: (Springer-Verlag)

Schlegel A, Alvarado S F and Wachter P. 1979. Optical Properties of Magnetite (Fe3O4), Journal of Physics C: Solid State Physics 12 1157-1164

Stuart D A, Haes A J, Yonson C R, Hicks E M and Van Duyne R P. 2005. Biological Application of Localised Surface Plasmonic Phenomenae IEE Proc-Nanobiotechnol Vol 152. No 1.

Verma R, Gupta B D and Jha R. 2011. Sensitivity enhancement of a surface plasmon resonance based biomolecules sensor using graphene and silicon layers Sensor and Actuators B: Chemical $160623-631$

Wang J, Sun Y, Wang L, Zhu X, Zhang H, Song D. 2010. Surface plasmon resonance biosensor based on Fe3)4/Au nanocomposites Colloid and Surfaces B: Biointerfaces $\mathbf{8 1}$ 600-606

Wu L, Chu H S, Koh W S and Li E P. 2010. Highly Sensitive Grphene Biosensors base on Surface Plasmon Resonance, Optics Express 1814 pp13143. 
THIS PAGE INTENTIONALLY LEFT BLANK 